\title{
Analysis and Design of Bowtie Antenna with Different Shapes and Structures
}

\author{
Babita Harchandra ${ }^{\#}$, Randhir Singh ${ }^{\#}$ \\ ${ }^{\#}$ Dept of E\&C, Sri Sai College of Engineering \& Technology, Badhani, Pathankot, Punjab-145001, India
}

\begin{abstract}
The demand of compact, efficient and economical communication devices has been tremendously increased. Same demand has been observed in antennas for multi-band applications. In this work, different designs of bowtie antennas are studied. The proposed antennas are designed, and results are evaluated to study different output parameters. The results confirmed that the proposed antennas may be useful for different mobile communication systems and Wireless applications. The results showed sufficient isolation among the operating frequency bands with improvement in gain and directivity. The results obtained had showed better improvement in the return loss and radiation pattern in comparison to the other existing antennas.
\end{abstract}

Keywords - Microstrip patch antenna, insertion loss, multi-band, mobile communication; bowtie antenna.

\section{INTRODUCTION}

In modern communication systems, light weighted, economical, compact, easy to carry and simple to use devices are in demand [1]. In this regard, the need of such antenna designs has been squeezed significantly by several researchers. To design an effective antenna, this becomes necessary to design it according to the theoretical calculations with proper external shapes and dimensions [2]. A microstrip element was invented and patented by Munson [3]. However, different microstrip geometries for antenna applications were studied by Weinschel [4]. The extensive work by Munson on the development of microstrip antennas gave birth to a new antenna industry [5]. During recent times, micromachining technology is developed that improves the antenna performance. Several methods have been reported to reduce the effective dielectric constant of substrate. High performance can be achieved by integrating the patch antenna on the low dielectric constant material with thick thickness [6-8].

The terms stripline and microstrip are often used while studying both transmission lines and microantennas. A stripline device is a sandwich of three parallel conducting layers separated by two thin dielectric substrates [8] [9]. If the center conductor couples to a resonant slot cut orthogonally in the upper conductor, the device is said to be a stripline radiator. In microstrip patch antennas, generally, two kinds of feeding are possible, i.e., coaxial probe feed and aperature coupled feed [10] [11]. Coaxial feed is the simplest feeding technique in microstrip antennas. In this, an inner conductor of coaxial line is attached to the radiating patch while outer conductor is connected to ground plane. It has spurious radiation because the radiating and feeding systems are disposed on two sides of ground plane and shielded from each other [12-14]. In aperature coupled feeding, the radiating patch is etched on the top of the antenna substrate and feed line is etched on the bottom of substrate. The thickness and dielectric constants of these two substrates may thus be chosen independently to optimize the distinct electrical functions of radiation and circuitry [15] [16].

In this work, a microstrip antenna with different bowtie arms is designed. Four different bowtie shapes were studied after theoretical analysis, i.e., parabolic bowtie, triangular bowtie, bow shaped, and circular shaped mirror arms. Aperture feed is used and the antennas are then analysed in accordance to the designed dimensions and geometries. Further, the designed antennas are evaluated for results in the form of output parameters.

\section{ANTENNA GEOMETRY}

The model is designed using commercial finite element method solver for electromagnetic structures supported HFSS (high frequency structural simulator) software. 3D modelling is done on the Arlon CuClad 217 (tm) substrate. Figure 1 shows the geometries of the different designs selected to develop and analyze the Coplanar Waveguide (CPW) fed bowtie antenna's. It consists of two mirror structures on the 
rectangular patch. A lumped port excitation is used for the CPW feed. The dimensions of the proposed antennas are set using theoretical analysis. The output parameters depend on the distance, position and the orientation of the bowtie.

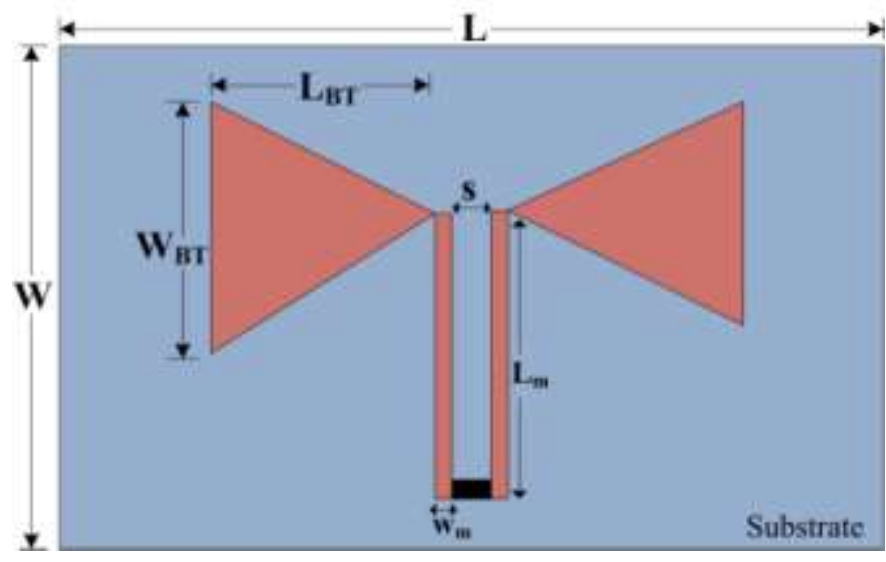

Fig. 1 Schematic showing shape and dimensional names of bowtie antenna TABLE I

PARAMETERS AND DIMENSIONS OF THE PROPOSED BOWTIE ANTENNAS

\begin{tabular}{|l|l|}
\hline \multicolumn{1}{|c|}{ Parameters } & \multicolumn{1}{c|}{ Dimensions (mm) } \\
\hline Length of the substrate, $\mathrm{L}$ & 70 \\
\hline Width of the substrate, $\mathrm{W}$ & 55 \\
\hline Bowtie arm length, $\mathrm{L}_{\mathrm{BT}}$ & 23.6 \\
\hline Bowtie arm width, $\mathrm{W}_{\mathrm{BT}}$ & 26 \\
\hline Spacing between feed line slots, $\mathrm{s}$ & 6 \\
\hline Sot length, $\mathrm{L}_{\mathrm{m}}$ & 34 \\
\hline Slot width, $\mathrm{W}_{\mathrm{m}}$ & 1.2 \\
\hline Height of the substrate, $\mathrm{h}$ & 1.6 \\
\hline
\end{tabular}

The width, $\mathrm{W}$ and length, $\mathrm{L}$ of the patch are calculated by using the transmission line model. The width of the rectangular patch, $\mathrm{W}$ is given by using Equation

$$
\mathrm{W}=\frac{\mathrm{c}}{2 \mathrm{f}_{0} \sqrt{\frac{\left(\varepsilon_{\mathrm{r}}+1\right)}{2}}}
$$

The effective dielectric constant, can be obtained by using Equation

$\mathrm{E}_{\text {reff }}=\frac{\varepsilon_{\mathrm{r}}+1}{2}+\left(\frac{\varepsilon_{\mathrm{r}}-1}{2}\right)\left[1+12\left(\frac{\mathrm{h}}{\mathrm{W}}\right)\right]^{-\frac{1}{2}}$
The length extension of the patch, can be obtained by using equation

$$
\Delta \mathrm{L}=0.412 \mathrm{~h}\left[\frac{\left(\mathrm{E}_{\text {reff }}+0.3\right)\left(\frac{\mathrm{W}}{\mathrm{h}}+0.264\right)}{\left(\mathrm{E}_{\text {reff }}-0.258\right)\left(\frac{\mathrm{W}}{\mathrm{h}}+0.8\right)}\right]
$$

The actual length of rectangular patch, $\mathrm{L}$ is calculated by using equation

$$
L_{\text {eff }}=\frac{c}{2 f_{0} \sqrt{E_{\text {reff }}}} L=L_{\text {eff }}-2 \Delta L
$$

where $L_{\text {eff }}$ is the effective length and is calculated as

$$
L_{\text {eff }}=\frac{c}{2 f_{0} \sqrt{E_{\text {reff }}}}
$$

For proper antenna designs, some finite ground plane is necessary below the substrate. Similarly, for practical design of microstrip patch antenna, it is essential that the ground plane should be greater than the actual patch dimensions by about six times the substrate thickness [14-16]. Thus, the dimensions of the ground plane may be given as

$$
\mathrm{L}_{\mathrm{g}}=6 \mathrm{~h}+1
$$

$\mathrm{W}_{\mathrm{g}}=6 \mathrm{~h}+\mathrm{w}$

The input parameters of the microstrip patch antenna are estimated using these above equations.

\section{RESULTS AND DISCUSSIONS}

The proposed design is simulated on the computational machine with processing speed of $2.6 \mathrm{GHz}$ and 4 GB RAM. The virtual memory used during simulation is $2.1 \mathrm{GHz}$. A precise sized meshing is not selected to avoid the computational load. Frequency domain setting is selected for simulating the model. The characteristic impedance $\left(\mathrm{Z}_{0}\right)$ of the simulated design comes out to be $50 \Omega$. Figure 2 shows the 4 different proposed designs of the bowtie antenna while Figure 3 shows the polar graph showing different radiation patterns. 


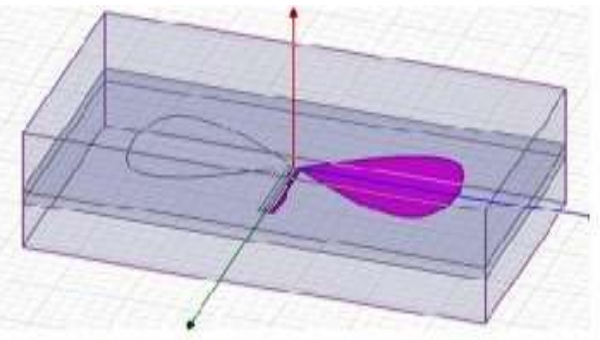

(a) Parabolic shaped bowtie antenna

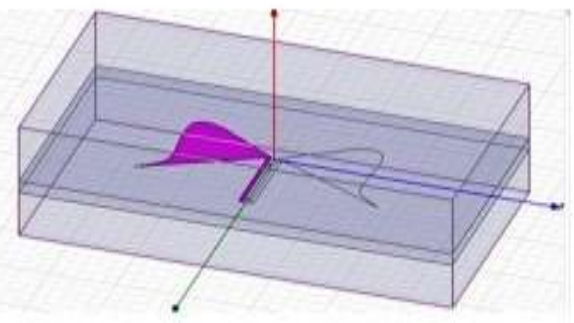

(c) Bow shaped bowtie antenna

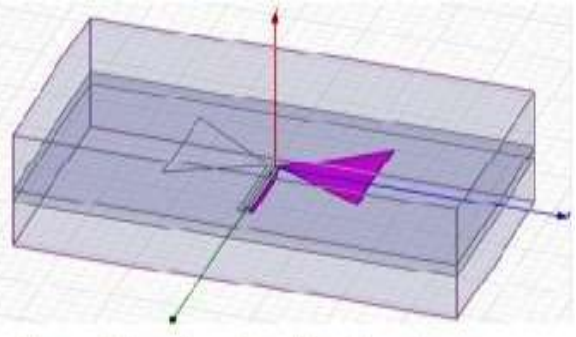

(b) Triangular shaped bowtie antenna

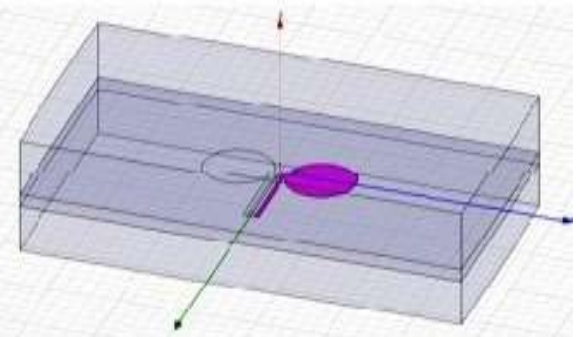

(d) Circular shaped bowtie antenna

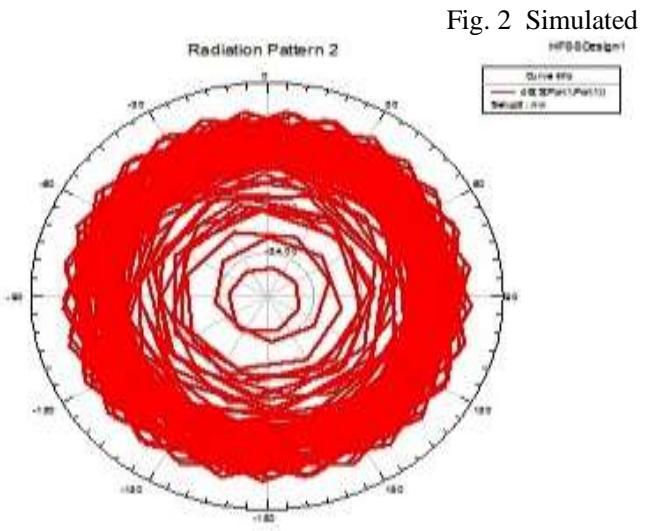

(a)

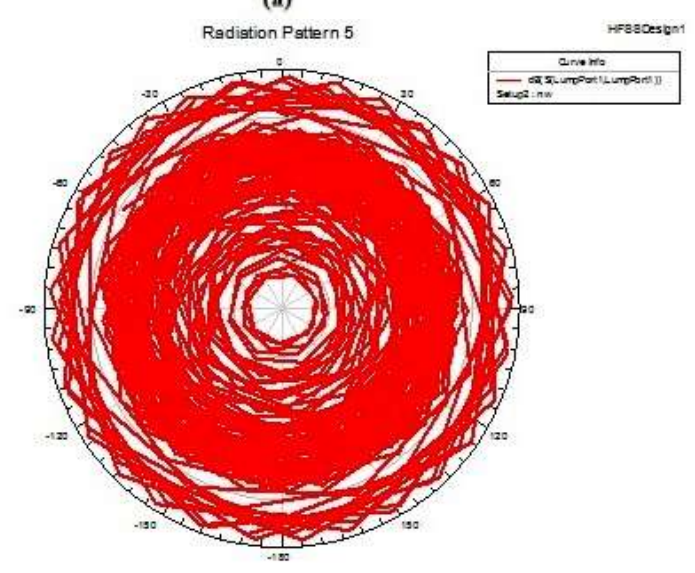

(c)

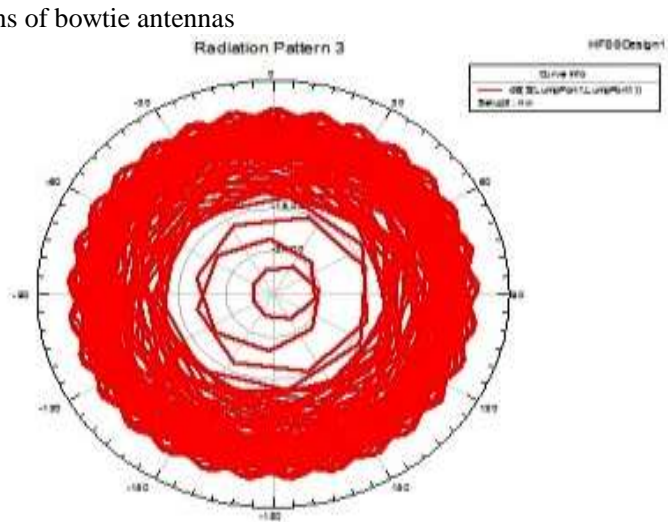

(b)

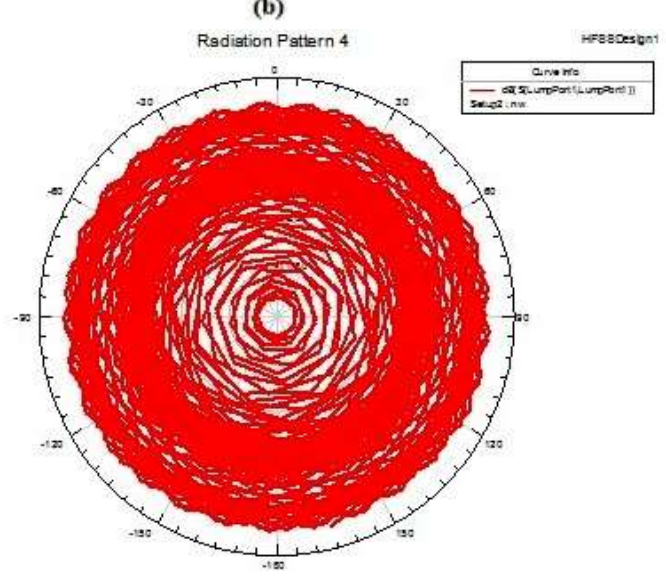

(d)

Fig. 3 Radiation patterns of simulated bowtie antennas

The designed antennas are then enclosed in the the return loss of the CPW fed bowtie antennas. rectangular air box. Figure 4 shows the return losses Parabolic bowtie antenna shows satisfactory results for the proposed antenna designs. Figure 4(a) shows 
International Journal of Engineering Trends and Technology (IJETT) - Volume 18 Number 4-Dec 2014 for dual frequencies. The return loss at $6.8 \mathrm{GHz}$ and $14.9 \mathrm{GHz}$ is $-18.0 \mathrm{~dB}$ and $-26.0 \mathrm{~dB}$.

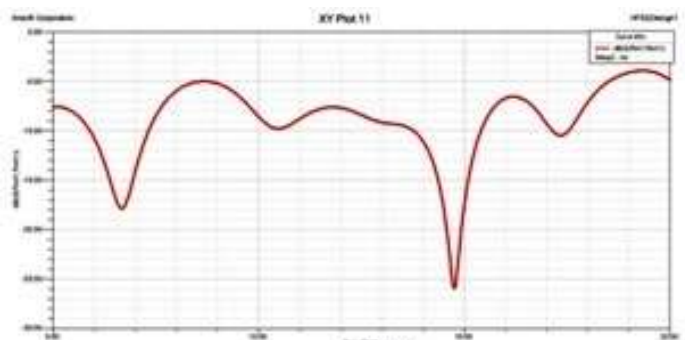

(a)

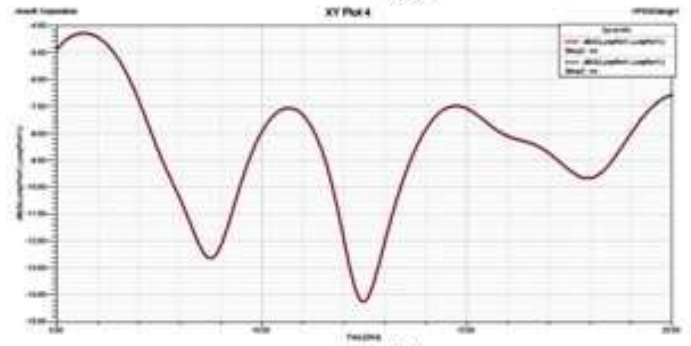

(c)

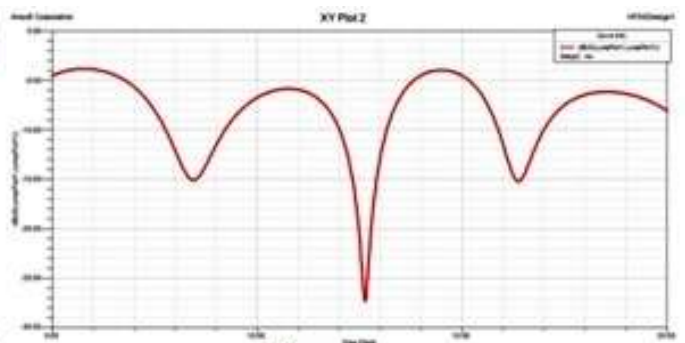

(b)

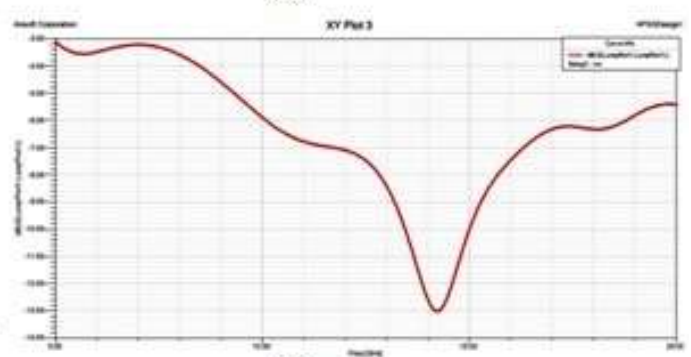

(d)

Fig. 4 Graphs showing insertion losses of their respective antennas

The Figure 4(b) shows the insertion loss for triangular bowtie antenna with triple band applications. The return loss at $8.5 \mathrm{GHz}, 12.6 \mathrm{GHz}$, and $16.4 \mathrm{GHz}$ is $-15.05 \mathrm{~dB},-27.50 \mathrm{~dB}$, and -15.1 $\mathrm{dB}$. Figure 4(c) shows the return loss of the bow shaped bowtie antenna. The return loss at $8.7 \mathrm{GHz}$
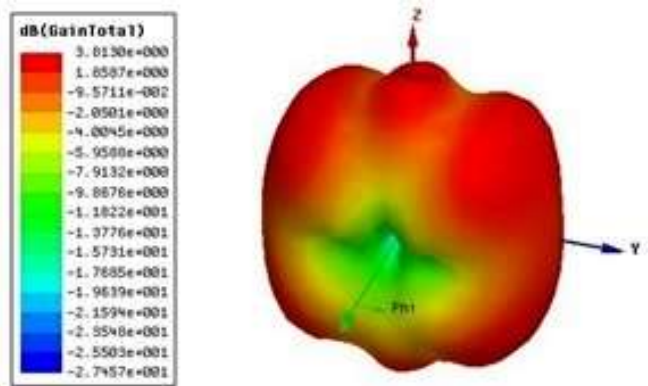

(a)
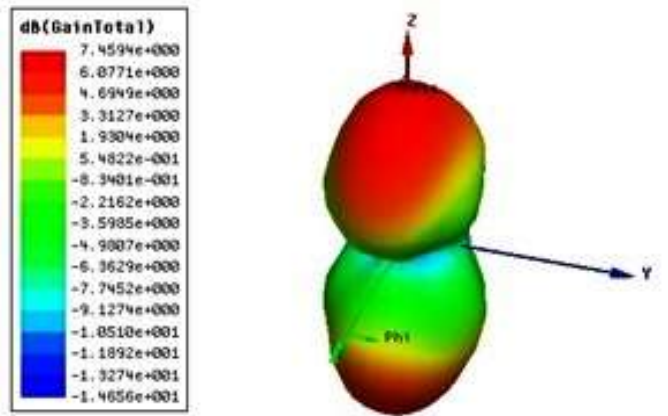

(c) and $13.5 \mathrm{GHz}$ is $-12.6 \mathrm{~dB}$ and $-14.3 \mathrm{~dB}$. Figure $4(\mathrm{~d})$ shows the return loss of the single band circular bowtie antenna. The return loss at $14.3 \mathrm{GHz}$ is -13 $\mathrm{dB}$.

Figure 5 shows the gain in $\mathrm{dB}$ for different proposed antennas.
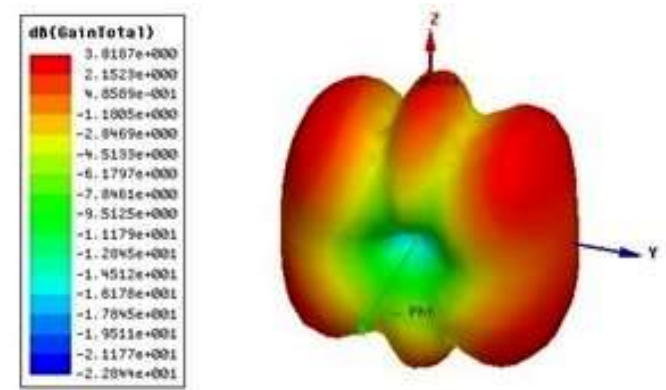

(b)
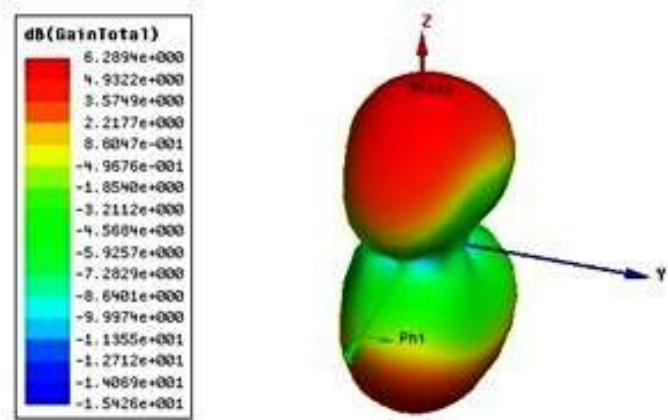

(d)

Fig. 5 Antenna gains of their corresponding designs 
The electric field distribution characteristics indicate that all the resonant modes for different coaxial positions can be tuned and controlled independently. Results show that despite a small distortion, the radiation patterns are reasonably well enough to work in different frequency bands.

\section{CONCLUSIONS}

In this paper, four different multi-frequency microstrip bowtie antennas are designed by using lumped port excitation with CPW feed. These antennas are used to design a single, dual, and triple, band antenna. This design is based on mono layer, single patch and does not require complex circuitry. The gain of the antenna is as high $9.01 \mathrm{~dB}$ and as smaller as $-2.7 \mathrm{~dB}$ value of gain. The characteristic impedance is fixed and accurate at $50 \mathrm{ohm}$. The proposed antenna designs can handle mutlifrequencies by simply changing the bowtie shapes and covers lot of demanding frequency bands used in everyday communication systems.

\section{REFERENCES}

[1] Y. P. Zhang and J. J. Wang, "Theory and analysis of differentially-driven microstrip antennas, "IEEE Transactions on Antennas and Propagation, Vol. 54, pp. 1092-1099, 2006.

[2] K. P. Yang and K. L. Wong, "Dual band circularly polarized square microstrip antenna," IEEE Trans. Antennas Propagat., Vol. 49, No. 3, 378-382, March 2001.

[3] E. Munson, "Single slot cavity antennas assembly," U.S. Patent No. 3713 162, Jan. 23, 1973.

[4] H. D. Weinschel, "Progress report on development of microstrip cylindrical arrays for sounding rockets," Physic. and Sci. Lab., New Mexico State Univ., Las Cruces, 1973.
[5] K. Buell, H. Mosallaei and K. Sarabandi, "A substrate for small patch antennas providing tunable miniaturization factor," IEEE Trans. Microwave Theory Tech., Vol. 54, 135-139, 2006.

[6] D. M. Pozar, Microwave Engineering: Wiley Inter-science, 2006.

[7] R. Chair, C. L. Mak, K. F. Lee, K. M. Luk, A. A. Kishk, "Miniature wide-band half U-slot and half E-shaped patch antennas," IEEE Transactions on Antennas and Propagation., Vol. 53, pp. 2645-2652, 2005.

[8] H. Nakano, K. Vichien, "Dual-Frequency Patch Antenna with a Rectangular Notch," Electronics Letters, vol. 25, No. 16, pp. 1067-1068, 1989.

[9] S. Arya, S. Khan, C. Shan, P. K. Lehana, "Design of a Microstrip Patch Antenna for Mobile Wireless Communication Systems," Journal of Computational Intelligence and Electronic Systems, Vol. 1, No. 2, pp. 178-182, 2012.

[10] A. Aslam, F. A. Bhatti, "Matching Technique for Microstrip Patch Antenna Using GCPW Feed," International Conference on Emerging Technologies, pp. 66 - 69, 2009.

[11] R. Arora, A. Kumar, S. Khan, S. Arya, "Finite Element Modeling and Design of Rectangular Patch Antenna with Different Feeding Techniques," Open journal of Antenna and Propagation, vol. 1, no. 1, 2013.

[12] S. Arya, S. Khan, C. K. Shan, P. Lehana, "Design of Small Integrated Antenna for Peer to Peer Wireless Communication," International Journal of Mobile Network Communications \& Telematics, Vol. 2, no. 3, pp. 11-20, 2012,

[13] R. Arora, A. Kumar, S. Khan, S. Arya, "Design Analysis and Comparison of HE shaped and E Shaped Microstrip Patch Antennas," International Journal on Communications Antenna and Propagation, Vol. 4, no. 1, pp. 27-31, 2014.

[14] L. C. Tsai, "A Dual-Band Bow-Tie-Shaped CPW-Fed Slot Antenna for WLAN Applications," Progress In Electromagnetics Research C, Vol. 47, 167-171, 2014.

[15] J. P. DeVilliers, and J.P.Jacobs, "Gaussian process modeling of CPW-fed slot antennas," Progress In Electromagnetics Research, Vol. 98, 233-249, 2009.

[16] C. Y. Huang, C. C. Lin, and W. F.Chen, "Multiple band-stop bow-tie slot antennas for multiband wireless systems," IET Micro., Ant. Propag., Vol. 2, No. 6, 588-593, Jun. 2008. 